\title{
Supervisi Klinik Stase Mayor Pada Rumah Sakit Pendidikan Fakultas Kedokteran dan IImu Kesehatan Universitas Jambi
}

\author{
Nyimas Natasha Ayu Shafira, Ahmad Syauqy \\ Faculty of Medicine and Health Sciences Jambi University \\ Email : nyimasnatasha@gmail.com
}

\begin{abstract}
Background: Clinical phase in medical education is education that carried out through the teaching and learning process in the form of clinical and community learning that employs various forms and levels of health services. At clinical phase learning, students are given the opportunity to be involved in health services with the guidance and supervision of clinical supervisors. Clinical supervision has a positive impact on patient health and the knowledge development of medical students.

Research Objective: This study aims to determine the clinical supervision overview in the major stage at Teaching Hospital of Faculty of Medicine and Health Sciences Jambi University based on student perceptions.
\end{abstract}

Method: This research is a combination of quantitative research and qualitative research. Quantitative research conducted was a cross sectional study using the Clinical Teaching Effectiveness Instrument (CTEI) questionnaire. The usage of the CTEI questionnaire in this study was to find out the clinical supervision overview in the major stage at Teaching Hospital based on student perceptions. Furthermore, qualitative research was conducted with focus group discussions (FGD) to confirm and explore the perceptions of the students based on the results of questionnaire analysis.

Results: Overall, for every 15 items of clinical supervision in each major stage had a mean CTEI score $>3$ with a score range of 3.6- 4.1. Range of scores on the Internal Medicine Department 3.2 - 4.7; Pediatric Department 3.4 - 3.8; Surgery Department 3.6 - 4 and Obgyn Department 3.7- 4.

Conclusion: Based on the results, it can be concluded that the clinical supervision of the major stages at Teaching Hospital of Faculty of Medicine and Health Sciences Jambi University has been run well.

Keywords: clinical supervision, CTEI, medical students

\section{ABSTRAK}

Latar Belakang: Pendidikan kedokteran fase klinik adalah pendidikan kedokteran yang dilaksanakan melalui proses belajar mengajar dalam bentuk pembelajaran klinik dan pembelajaran komunitas yang menggunakan berbagai bentuk dan tingkat pelayanan kesehatan nyata. Pada pembelajaran fase klinik mahasiswa diberi kesempatan terlibat dalam pelayanan kesehatan dengan bimbingan dan pengawasan supervisor klinik . Supervisi klinik memiliki dampak yang positif terhadap kesehatan pasien dan perkembangan pengetahuan mahasiswa kedokteran.

Tujuan Penelitian: Penelitian ini bertujuan untuk mengetahui gambaran supervisi klinik di stase mayor Rumah Sakit pendidikan Fakultas Kedokteran dan IImu Kesehatan Universitas Jambi berdasarkan persepsi mahasiswa

Metode: Penelitian ini merupakan gabungan antara penelitian kuantitatif dan penelitian kualitatif. Penelitian kuantitatif yang dilakukan merupakan, studi cross sectional dengan menggunakan kuesioner Clinical Teaching Effectiveness Instrument (CTEI). Penggunaan kuesioner CTEI pada penelitian ini untuk mengetahui gambaran supervisi klinik di stase mayor Rumah Sakit pendidikan berdasarkan persepsi mahasiswa. Selanjutnya dilakukan penelitian kualitatif dengan diskusi kelompok terfokus 
(DKT) untuk mengkonfirmasi dan mengeksplorasi persepsi mahasiswa tersebut berdasarkan hasil analisis kuesioner

Hasil: Secara keseluruhan untuk setiap 15 item supervisi klinik di setiap bagian mayor memiliki rerata skor CTEI > 3 dengan rentang skor 3.6- 4.1. Rentang skor pada Bagian IImu penyakit Dalam 3.2 - 4.7; Bagian IImu kesehatan anak 3.4 - 3.8; Bagian IImu Bedah 3.6 - 4 dan Bagian Obgyn 3.7- 4.

Kesimpulan: Berdasarkan hasil penelitian dapat disimpulkan bahwa supervisi klinis stase mayor di Rumah Sakit Pendidikan Fakultas Kedokteran dan IImu Kesehatan Universitas Jambi telah berjalan dengan baik.

Kata kunci: supervisi klinik, CTEl, mahasiswa kedokteran

\section{Pendahuluan}

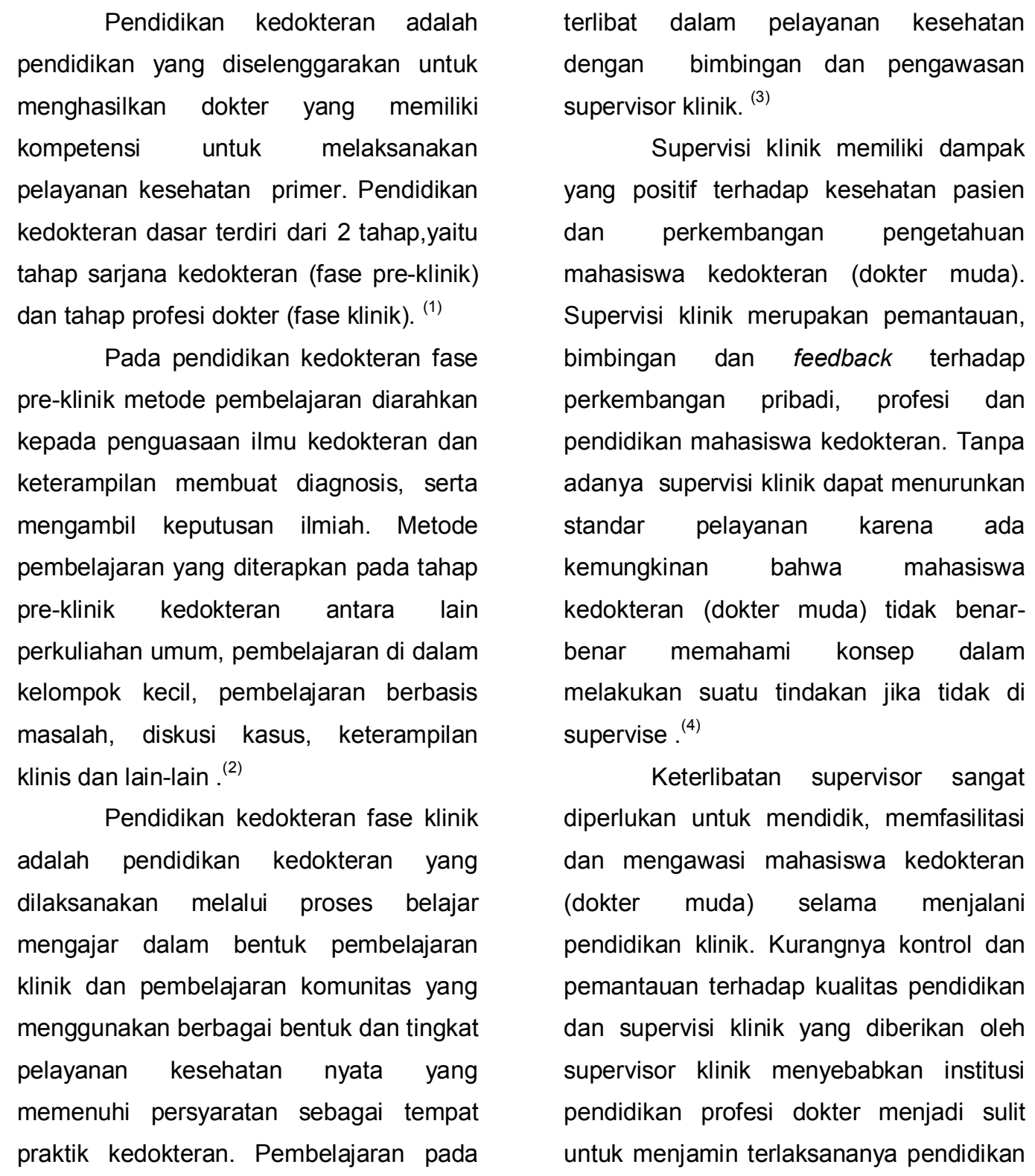
fase klinik mahasiswa diberi kesempatan 
dan pengawasan klinik yang berkualitas (5)

\section{Metode}

Penelitian ini merupakan gabungan antara penelitian kuantitatif dan penelitian kualitatif. Penelitian kuantitatif yang dilakukan merupakan, studi cross sectional dengan menggunakan kuesioner Clinical Teaching Effectiveness Instrument (CTEI). Penggunaan kuesioner CTEI pada penelitian ini untuk mengetahui gambaran supervisi klinik di stase mayor Rumah Sakit pendidikan Fakultas Kedokteran dan IImu Kesehatan Universitas Jambi berdasarkan persepsi mahasiswa. Selanjutnya dilakukan penelitian kualitatif dengan diskusi kelompok terfokus (DKT) untuk mengkonfirmasi dan mengeksplorasi persepsi mahasiswa tersebut berdasarkan hasil analisis kuesioner.
Pengumpulan data penelitian dilaksanakan dengan memakai kuesioner Clinical Teaching Effectiveness Instrument (CTEI)) kepada mahasiswa program profesi dokter yang telah menjalani rotasi klinik stase mayor. Jumlah mahasiswa yang bersedia mengisi kuesioner adalah 55 orang.

\section{Gambaran Supervisi Klinik Stase Mayor pada Rumah Sakit Pendidikan FKIK UNJA}

Pada tabel 1 didapatkan hasil analisis univariat untuk setiap item supervisi klinik pada setiap stase mayor. Secara keseluruhan untuk setiap 15 item supervisi klinik di setiap bagian mayor memiliki rerata skor $\mathrm{CTEI}>3$ dengan rentang skor 3.6- 4.1. Rentang skor pada stase IImu penyakit Dalam (IPD) 3.2 - 4.7; stase IImu kesehatan anak (IKA) 3.4 3.8; stase IImu Bedah 3.6 - 4 dan stase Obgyn 3.7- 4.

\section{Hasil}

Tabel 5.1 Gambaran Supervisi Klinik Stase Mayor pada Rumah Sakit Pendidikan FKIK UNJA 


\begin{tabular}{|c|c|c|c|c|c|c|}
\hline & & IPD & IKA & BEDAH & OBGYN & \\
\hline 1 & $\begin{array}{l}\text { Menciptakan lingkungan belajar yang baik (ramah/ } \\
\text { mudah di dekati, tidak ada ancaman, antusias dalam } \\
\text { membimbing, dll) }\end{array}$ & 3.3 & 3.6 & 4 & 3.9 & 3.7 \\
\hline 2 & $\begin{array}{l}\text { Menstimulasi mahasiswa untuk belajar mandiri } \\
\text { (misalnya memberi penugasan ). }\end{array}$ & 4.7 & 3.7 & 3.8 & 4 & 4.1 \\
\hline 3 & $\begin{array}{c}\text { Mengijinkan mahasiswa untuk melakukan tugas klinik } \\
\text { sesuai dengan tingkatan/pengalaman/kompetensi } \\
\text { mahasiswa }\end{array}$ & 3.5 & 3.7 & 3.8 & 4 & 3.8 \\
\hline 4 & $\begin{array}{c}\text { Mengatur waktu, baik untuk pelayanan maupun } \\
\text { pengajaran }\end{array}$ & 4.3 & 3.4 & 3.8 & 3.9 & 3.9 \\
\hline 5 & $\begin{array}{l}\text { Memberikan umpan balik/ masukan secara teratur } \\
\text { terhadap kemampuan klinik mahasiswa. }\end{array}$ & 3.4 & 3.5 & 3.7 & 3.8 & 3.6 \\
\hline 6 & $\begin{array}{c}\text { Merinci dengan jelas apa yang diharapkan untuk } \\
\text { mahasiswa ketahui dan lakukan selama masa rotasi } \\
\text { klinik di bagian tersebut. }\end{array}$ & 3.4 & 3.7 & 3.6 & 3.8 & 3.6 \\
\hline 7 & $\begin{array}{l}\text { Menyesuaikan pengajaran sesuai dengan kebutuhan } \\
\text { mahasiswa (tujuan pembelajaran dan kompetensi). }\end{array}$ & 3.4 & 3.8 & 3.8 & 3.8 & 3.7 \\
\hline 8 & Mengajukan pertanyaan yang memacu belajar & 3.7 & 3.7 & 3.8 & 3.8 & 3.8 \\
\hline 9 & $\begin{array}{l}\text { Memberikan penjelasan/ alasan yang jelas untuk setiap } \\
\text { pendapat, nasihat, tindakan. }\end{array}$ & 3.5 & 3.7 & 3.7 & 3.9 & 3.7 \\
\hline 10 & $\begin{array}{l}\text { Menyesuaikan pengajaran di tempat yang bervariasi } \\
\text { (bedside,ruang operasi, ruang pemeriksaan, } \\
\text { laboraturium) }\end{array}$ & 3.4 & 3.7 & 3.9 & 3.8 & 3.7 \\
\hline 11 & $\begin{array}{c}\text { Mendampingi siswa saat melakukan ketrampilan } \\
\text { klinik/tehnik (anamnesis, pemeriksaan fisik, } \\
\text { keterampilan prosedural) }\end{array}$ & 3.6 & 3.7 & 3.7 & 3.7 & 3.7 \\
\hline 12 & $\begin{array}{l}\text { Menggunakan data penelitian dan atau pedoman } \\
\text { praktek dalam mengajar }\end{array}$ & 3.2 & 3.5 & 3.7 & 3.7 & 3.5 \\
\hline 13 & $\begin{array}{l}\text { Mengajarkan cara menegakkan diagnosis (penalaran } \\
\text { klinis, interprestasi hasil pemeriksaan) }\end{array}$ & 4.0 & 3.8 & 3.9 & 4 & 3.9 \\
\hline 14 & $\begin{array}{c}\text { Mengajarkan ketrampilan komunikasi pasien dan/atau } \\
\text { keluarga yang efektif }\end{array}$ & 3.8 & 3.7 & 3.7 & 3.9 & 3.8 \\
\hline 15 & $\begin{array}{l}\text { Mengajarkan prinsip-prinsip pelayanan kesehatan tepat } \\
\text { biaya (pemilihan alat pemeriksaan dan pemilihan obat). }\end{array}$ & 3.4 & 3.4 & 3.6 & 3.8 & 3.6 \\
\hline
\end{tabular}

Berdasarkan hasil diskusi kelompok terfokus yang memfokuskan membahas pengalaman supervisi klinik pada setiap stase mayor. Untuk item supervisi klinik "Menciptakan lingkungan belajar yang baik (ramah/ mudah di dekati, tidak ada ancaman, antusias dalam membimbing, dII)" . Mahasiswa menjelaskan hal tersebut memang mereka temui di setiap stase mayor yang mereka jalani. Mereka menjelaskan supervisor klinik mudah ditemui dan memberikan kesempatan mahasiswa terlibat aktif dalam pembelajaran.

Berdasarkan keterangan mahasiswa. mereka menyetujui bahwa supervisi klinik di setiap bagian mayor
"Menstimulasi mahasiswa untuk belajar mandiri (misalnya memberi penugasan )." Hal ini dijelaskan oleh mahasiswa bahwa disetiap kegiatan case report session (CSS), laporan jaga mereka selalu diberi tugas mandiri oleh supervisor klinik yang membimbing. Mahasiswa juga menjelaskan bahwa di setiap stase mayor supervisor klinik "Mengijinkan mahasiswa untuk melakukan tugas klinik sesuai dengan tingkatan/pengalaman/kompetensi mahasiswa".

Mahasiswa menjelaskan bahwa pembelajaran rotasi klinik mereka dimulai sebelum jam poliklinik dan setelah jam poliklinik. Mereka juga terlibat pada saat pelayanan di poliklinik, hal ini 
menunjukkan Supervisor klinik di stase mayor juga "Mengatur waktu, baik untuk pelayanan maupun pengajaran".

Di setiap stase mayor setiap supervisor klinik "Memberikan umpan balik/ masukan secara teratur terhadap kemampuan klinik mahasiswa". Menurut mahasiswa hal ini biasanya terjadi pada saat kegiatan bed side teaching (BST).

Menurut penjelasan mahasiswa supervisi klinik di setiap bagian mayor juga "Merinci dengan jelas apa yang diharapkan untuk mahasiswa ketahui dan lakukan selama masa rotasi klinik di bagian tersebut".Mahasiswa juga menjelaskan bahwa supervisi klinik tersebut telah "Menyesuaikan pengajaran sesuai dengan kebutuhan mahasiswa (tujuan pembelajaran dan kompetensi)". Kedua hal ini disampaikan di awal permulaaan rotasi klinik sebelum mereka memulai pembelajaran . Mahasiswa juga diberikan logbook yang akan menjadi panduan mereka selama pembelajaran di stase mayor tersebut.

Mahasiswa juga berpendapat bahwa setiap supervisor klinik selalu "Mengajukan pertanyaan yang memacu belajar" dan "Memberikan penjelasan/ alasan yang jelas untuk setiap pendapat, nasihat, tindakan". Hal ini terjadi pada kegiatan BST, CRS, laporan jaga dan saat mahasiswa mendampingi supervisor klinik melakukan tindakan prosedural kepada pasien.

Kegiatan supervisi klinik di stase mayor juga "Menyesuaikan pengajaran di tempat yang bervariasi (bedside,ruang operasi, ruang pemeriksaan, laboraturium)". Hampir semua stase mayor melaksanakan kegiatan pembelajaran diberbagai tempat tersebut. Mahasiswa juga menjelaskan supervisi klinik di stase mayor "Mendampingi siswa saat melakukan ketrampilan klinik/tehnik (anamnesis, pemeriksaan fisik, keterampilan prosedural)". Serta "Menggunakan data penelitian dan atau pedoman praktek dalam mengajar". Hal ini terjadi pada kegiatan BST, supervisor klinik selalu mendampingi mahasiswa dalam kegiatan tersebut dan menggunakan pedoman praktek yang sudah ada.

Supervisi klinik di stase mayor juga "Mengajarkan cara menegakkan diagnosis (penalaran klinis,interprestasi hasil pemeriksaan)" dan "Mengajarkan ketrampilan komunikasi pasien dan/atau keluarga yang efektif “. Mahasiswa juga menjelaskan bahwa pada stase mayor mereka "Mengajarkan prinsip-prinsip pelayanan kesehatan tepat biaya (pemilihan alat pemeriksaan dan pemilihan obat) “. Menurut mahasiswa selama mengikuti pembelajaran di stase mayor mereka dilatih untuk menegakkan diagnosis berdasarkan kemampuan anamnesis dan juga pemeriksaan fisik. Oleh karena itu supervisor klinik selalu memberikan feedback terhadap kemampuan komunikasi terutama kemampuan anamnesis mahasiswa. Supervisor klinik juga mengajarkan bagaimana memilih pengobatan dan pemeriksaaan penunjang yang tepat sesuai dengan kondisi pasien.

\section{Pembahasan}


Hasil analisis gambaran supervisi klinis stase mayor di Rumah Sakit Pendidikan RSUD Raden Mattaher FKIK UNJA secara keseluruhan rerata skor CTEI >3 dengan rentang skor 3,6- - 4.1 sehingga dapat disimpulkan bahwa supervisi klinis stase mayor di Rumah Sakit Pendidikan RSUD Raden Mattaher FKIK UNJA adalah baik berdasarkan persepsi mahasiswa.

Hasil penelitian ini sejalan dengan penelitian yang dilakukan Dian Apriliana tentang persepsi mahasiswa terhadap kualitas supervisi klinik di 12 Rumah Sakit Jejaring FK UNISULA nilai rata-rata skor CTEl >3 dengan rentang skor 3,25 - 4,02 sehingga secara keseluruhan keefektifan supervisi klinik dinilai baik. ${ }^{(5)}$

Supervisi klinik sangat penting dalam pendidikan kedokteran, tanpa adanya supervisi klinik yang baik, mahasiswa tidak dapat belajar secara efektif dari pengalaman mereka di rotasi klinik. Hal ini tentunya dapat menurunkan kualiatas pelayanan kesehatan . ${ }^{(6)}$

Spencer menyatakan terdapat beberapa tantangan yang mungkin akan dijumpai dalam pengajaran klinis yaitu: tekanan waktu, beban kerja supervisor klinis, mahasiswa yang memiliki kemampuan yang bervariasi, hambatan terkait pasien (periode rawat inap singkat, pasien sakit parah, dan pasien tidak mau terlibat dalam proses pengajaran klinis), sedikitnya insentif dan penghargaan untuk pengajar, dan lingkungan pembelajaran yang tidak nyaman. ${ }^{(7)}$

Supervisi klinik akan menjadi efektif apabila: ${ }^{(4)}$
1. Supervisi klinis terselenggara sesuai dengan konteksnya, supervisor harus tahu dan memahami materi pelatihan dan kebutuhan institusi.

2. Ada supervisi langsung, dimana supervisor dan peserta didik bekerja sama dan saling mengamati.

3. Constructive feedback sangat diperlukan dan harus sering diberikan kepada peserta didik.

4. Supervisi klinik harus terstruktur dan harus ada pertemuan rutin.

5. Supervisi klinik harus memasukkan managemen klinik, pengajaran dan penelitian, manajemen dan administrasi, pastoral care, ketrampilan interpersonal, pengembangan pribadi serta refleksi.

6. Kualitas hubungan dalam supervisi klinik yang baik.

Supervisi klinik harus memiliki struktur, aturan dasar dan tujuan pembelajaran yang bersifat fleksibel. Apa yang cocok untuk satu spesialisasi tertentu mungkin tidak cocok untuk yang lain. Salah satu faktor yang paling penting adalah hubungan dalam supervisi klinik. Konsultan harus bertindak sebagai role model, tetapi bukan satu arah mahasiwa tetap memiliki kontrol atas pembelajarannya dan terlibat dalam proses pembelajaran. Oleh karena itu sistem pendidikan kedokteran harus memastikan adanya hak untuk mendapatkan supervisi, umpan balik, dukungan, kondisi kerja yang layak dan 
sikap menghormati baik mahasiswa

maupun supervisornya. ${ }^{(6)}$

\section{Kesimpulan}

Berdasarkan hasil penelitian dan pembahasan yang telah diuraikan sebelumnya, dapat diambil kesimpulan bahwa supervisi klinis stase mayor di

Rumah Sakit Pendidikan Fakultas

Kedokteran dan IImu Kesehatan

Universitas Jambi telah berjalan dengan

baik.

\section{DAFTAR PUSTAKA}

1. KKI. Standar kompetensi dokter. Jakarta: Konsil Kedokteran Indonesia. 2012

2. Dent JA HR. A Practical Guide For Medical Teachers. 2nd ed. Edinburgh: Churchill Livingstone; 2005.

3. RI UU. Undang-Undang Republik Indonesia Nomor 20 Tahun 2013 Tentang Pendidikan Kedokteran. Jakarta: UU RI. 2013.

4. Kilminster S, Jolly B. Effective supervision in clinical practice settings: a literature review. Medical education. 2000;34(10):827-40.

5. Rahmawatie DA, Rahayu GR, Prihatiningsih TS. Persepsi Mahasiswa terhadap Kualitas Supervisi Klinik di 12 Rumah Sakit Jejaring FK Unissula Students Perceptions on the quality of clinical supervision among the 12 affiliated hospital of Medical Faculty of UNISSULA. Sains Medika. 2011;3(2):135-49.

6. Hore CT, Lancashire W, Fassett RG. Clinical supervision by consultants in teaching hospitals. Med J Aust. 2009;191(4):220-2.

7. Spencer J. $A B C$ of learning and teaching in medicine: Learning and teaching in the clinical environment. BMJ: British Medical Journal. 2003;326(7389):591. 